\title{
Influence of Elevation Data Source on 2D Hydraulic Modelling
}

\author{
Krzysztof BAKUŁA, Mateusz STĘPNIK, \\ and Zdzisław KURCZYNSSKI \\ Warsaw University of Technology, \\ Faculty of Geodesy and Cartography, Warsaw, Poland; \\ e-mails: k.bakula@gik.pw.edu.pl (corresponding author), \\ matstepnik@gmail.com, kurczynski@wp.pl
}

\begin{abstract}
The aim of this paper is to analyse the influence of the source of various elevation data on hydraulic modelling in open channels. In the research, digital terrain models from different datasets were evaluated and used in two-dimensional hydraulic models. The following aerial and satellite elevation data were used to create the representation of terrain digital terrain model: airborne laser scanning, image matching, elevation data collected in the LPIS, EuroDEM, and ASTER GDEM. From the results of five 2D hydrodynamic models with different input elevation data, the maximum depth and flow velocity of water were derived and compared with the results of the most accurate ALS data. For such an analysis a statistical evaluation and differences between hydraulic modelling results were prepared. The presented research proved the importance of the quality of elevation data in hydraulic modelling and showed that only ALS and photogrammetric data can be the most reliable elevation data source in accurate 2D hydraulic modelling.
\end{abstract}

Key words: digital terrain model (DTM), hydraulic modelling, LIDAR, aerial photogrammetry, satellite imagery. 


\section{INTRODUCTION}

To enable the accurate hydraulic modelling of inundation areas, a detailed and accurate digital terrain model of a watercourse (DTM-W) is required. It is the main input to numerical hydrodynamic modelling (not concerning flow resistance - the impact of the roughness), especially if two-dimensional (2D) modelling is considered. DTM-W is a digital terrain model (DTM) that describes the potential inundation area of a river, including the effects of the river bed and buildings hindering the run-off (Mandlburger and Brockmann 2001). According to a document prepared by a group of experts working in the European Exchange Circle on Flood Mapping (Martini and Loat 2007), the appropriate selection of elevation data source has a significant impact. The vertical accuracy of DTM should be better than $0.5 \mathrm{~m}$ (root mean square error-RMSE). Among the possible methods and tools providing DTM for large areas the following may be mentioned: airborne laser scanning, satellite and aerial radar systems, aerial digital images, high-resolution satellite images and DTM obtained from vectorization of contour lines from topographic maps on a scale of 1:10000 and contour interval of less than $0.5 \mathrm{~m}$ for flat areas.

In the literature, some experiments using various elevation sources in hydraulic modelling have been described (Casas et al. 2006, Cheveresan 2012). There are studies concerning smaller areas where the most accurate elevation data from airborne laser scanning were utilized in hydraulic modelling (French 2003, Mandlburger et al. 2009, Sole et al. 2008). This technique replaced photogrammetric methods of 3D data collection, which had been applied before the development of airborne laser scanning in the most accurate hydraulic analyses (Lane et al. 2002). For studies concerning large areas or areas sparsely covered with data, the examples of satellite elevation data, i.e., radar interferometry (Farr et al. 2007, Yamazaki et al. 2012, Wang et al. 2012), methods based on satellite stereo pairs providing global DTM (Rauter et al. 2009, Wang et al. 2012, Gichamo et al. 2012) or DTM created from contour lines vectorized from topographic maps at different scales (Casas et al. 2006, Cheveresan 2012) can be used. However, there are few studies comparing the available elevation data sources and their impact on the results of hydraulic modelling in the analysis of the same area. This paper presents a variety of height data used in two-dimensional flood wave propagation and assesses such influences.

\section{REMOTE SENSING ELEVATION DATA FOR HYDRAULIC MODELLING}

The digital terrain model is a numerical representation of terrain relief and it is applied as a boundary condition in 2D hydraulic modelling. The term was 
first used was by Miller and Laflamme (1958), and since then it was called by different names: digital elevation model (DEM), digital ground model (DGM), digital height model (DHM), and digital terrain elevation model (DTEM), which were associated with the nomenclature of experts from various fields of science and from different countries. In practice, despite their frequent usage as synonyms, their meaning is not the same (Li et al. 2005, Höhle and Potuckova 2011). Remote sensing elevation data sources can be divided into two groups: airborne and satellite data. Another classification related to the method of data acquisition distinguishes between active (i.e., laser scanning, radar interferometry) and passive (stereophotogrammetry) techniques.

\subsection{Airborne data}

At present, airborne laser scanning (ALS), also commonly called Light Detection and Ranging (LIDAR), is the most accurate remote sensing method of $3 \mathrm{D}$ data acquisition for terrain and its coverage. The principle of this method is a time-of-flight measurement of an outgoing laser pulse interacting with (multiple) targets within the laser beam (Wehr and Lohr 1999), which provide point clouds with specified $\mathrm{X}, \mathrm{Y}, \mathrm{Z}$ coordinates of thousands of points belonging to the surface of a terrain and objects on it (Kurczyński 2006). As a result of laser scanning, quasi-continuous spatial representation of terrain with a height accuracy of a few centimetres is provided. For instance, during the implementation of the EU Flood Directive (Directive 2007) in Poland, DTM based on the ALS technique had a resolution of $1 \mathrm{~m}$ and vertical accuracy of at least $\mathrm{RMSE}=0.15 \mathrm{~m}$ for uncovered, paved surfaces, and at least $\mathrm{RMSE}=0.30 \mathrm{~m}$ for forested areas (Kurczyński and Bakuła 2013).

The other technology that allows for highly accurate digital elevation model generation is automatic image matching, which also provides point clouds. Photogrammetric technology has a tradition of over 100 years in aerial image application for cartography. Current techniques of image acquisition with large-format digital cameras provide high-resolution data at a pixel resolution lower than $10 \mathrm{~cm}$. These images offer a great opportunity for image matching applications to replace stereo measurements. In recent years, algorithms of this technique have been significantly developed from areabased matching (ABM) and feature-based matching (FBM) methods to specialized algorithms of dense image matching providing point clouds comparable with ALS data (Hirschmüller 2008, Rothermel and Haala 2011). The disadvantage of this technique is the lack of penetration through vegetation, which means that DTM obtained with photogrammetric technology has low- 
er accuracy in forested areas and must be integrated with manual stereoscopic measurements or other surveying data.

In Poland, in national or regional repositories, digital terrain models have been prepaired. They were obtained by photogrammetric technology within the Land Parcel Identification System (LPIS). The direct objective of their creation was orthorectification of aerial images needed to produce orthophotomaps for system purposes, as well as to supply a topographic database at a scale of 1:10000. The basic source of these elevation data was stereoscopic measurements from aerial images (analogue at a scale of $1: 13000$ or digital with ground sampling distance GSD $=0.25 \mathrm{~m}$ ) with interior (parameters of camera) and exterior orientation (location and orientation of each image) defined in a bundle adjustment process. In cases of difficult land cover mostly related to vegetation, both types of measurement were allowed: manual (photogrammetric spatial resection) and automatic (image matching). The vertical accuracy of such a product is much lower due to the objectives of their generation. The approximate error for this DTM was estimated at below $0.6 \mathrm{~m}$ for flat and uncovered areas.

In the second half of the twentieth century, aerial photographs and stereoscopic observations in analogue technology became the elevation data source for topographic map generation. Vectorization of contours from these maps allowed for DTM creation, which is sufficient for a regional approximated representation of terrain topography. An example of such a model is EuroDEM - European DTM generated with a large share of contour lines from topographic maps on a scale of 1:100000. The vertical accuracy of EuroDEM is about 8-10 m (Hovenbitzer 2008); however, in Poland, maps on a scale of 1:50000 were adopted and so the accuracy of EuroDEM can be estimated at about 3-4 m.

\subsection{Satellite data}

Among the elevation data used to create global satellite elevation models, radar interferometry should be primarily indicated. The example of application of this technique is the space Shuttle Radar Topography Mission (SRTM) (Rabus et al. 2003). This global DTM covers $80 \%$ of land surface in two standards: SRTM-1 (resolution of 1 arcsec - approx. $30 \times 20 \mathrm{~m}$ ) and SRTM-3 (3 arcsec - approx. $90 \times 60 \mathrm{~m}$ ). Radar interferometry is still dynamically developed, which can be observed in the German satellite missions of TerraSAR-X and TanDEM-X (Krieger et al. 2007).

Another source of DTM is image matching of stereo images. Such highresolution images are captured by satellite sensors, which are able to change the angle of deflection and consequently register the same area from different locations (oblique imageries) - especially in the case of a single satellite 
transition (from one orbit). One of the first proposed DTMs generated with this technology was an ITM-1 (IKONOS Terrain Model-1) derived on request in two standards: ITM-5c w (resolution of $1 \mathrm{arcsec}$ ) and ITM-5e $(0.2$ arcsec $)$. At present, most satellites that register optical imageries are equipped with this measurement solution.

In recent years, another global terrain model has been developed. The ASTER Global Digital Elevation Model (ASTER GDEM) (Jacobsen and Passini 2010) was generated with more than one million stereo-pairs of images collected by the Japanese Advanced Spaceborne Thermal Emission Reflection Radiometer (ASTER). The model covers $99 \%$ of the land surface. Its spatial resolution is 1 arcsec and it has a declared vertical accuracy better than $20 \mathrm{~m}$. It is worth mentioning that satellite elevation data are strongly dependent upon the terrain morphology and land coverage, and the fact that they can be affected by systematic and random errors, so homogenous accuracy cannot be expected from this data source (Jacobsen and Passini 2010).

\subsection{Test area and data used in the experiment}

The test area is a part of the Połaniec Basin limited to two sections (M-34-55-A-d-4 and M-34-55-C-b-2) of the topographic map on a scale of 1:10 000 covering about $40 \mathrm{~km}^{2}$ (Fig. 1a). The research area is located in Rytwiany municipality, part of Staszów district in Świętokrzyskie Voivodeship. The river flowing through this area is the Czarna Staszowska. Figure 1 presents all elevation data used in the experiment. As the most accurate elevation data, an airborne laser scanning point cloud from 2012 with an average density of four points per square metre was used to generate the most accurate DTM at a $1 \mathrm{~m}$ resolution (Fig. 1b). The second data source was archival analogue aerial images obtained by a photogrammetric large-format camera in 2009 on a scale of 1:13 000 (scanned with the resolution of $14 \mu \mathrm{m}$, $\mathrm{GSD}=0.19 \mathrm{~m}$ ). They were used to create DTM at a $3 \mathrm{~m}$ resolution (Fig. 1c) using dense image matching techniques supplemented by stereoscopic measurements in forested areas. The third data source was DTM from the LPIS system (Fig. 1d), which has already been prepared and archived in a national repository, with a $10 \mathrm{~m}$ spatial resolution. The fourth was a part of EuroDEM (Fig. 1e) in a 2 arcsec (approx. $60 \times 40 \mathrm{~m}$ ) grid created from the vectorization of contours from topographic maps on a scale of 1:50000. Lastly, the fifth data source was a part of ASTER GDEM (Fig. 1f) at a $30 \mathrm{~m}$ resolution whose systematic vertical error was eliminated.

A preliminary analysis of the vertical accuracy of the data was associated with a comparison of heights interpolated from DTMs from different sources with respect to 150 points measured with GNSS observations in an area not covered by high vegetation. The results of this analysis are given in Table 1 . 

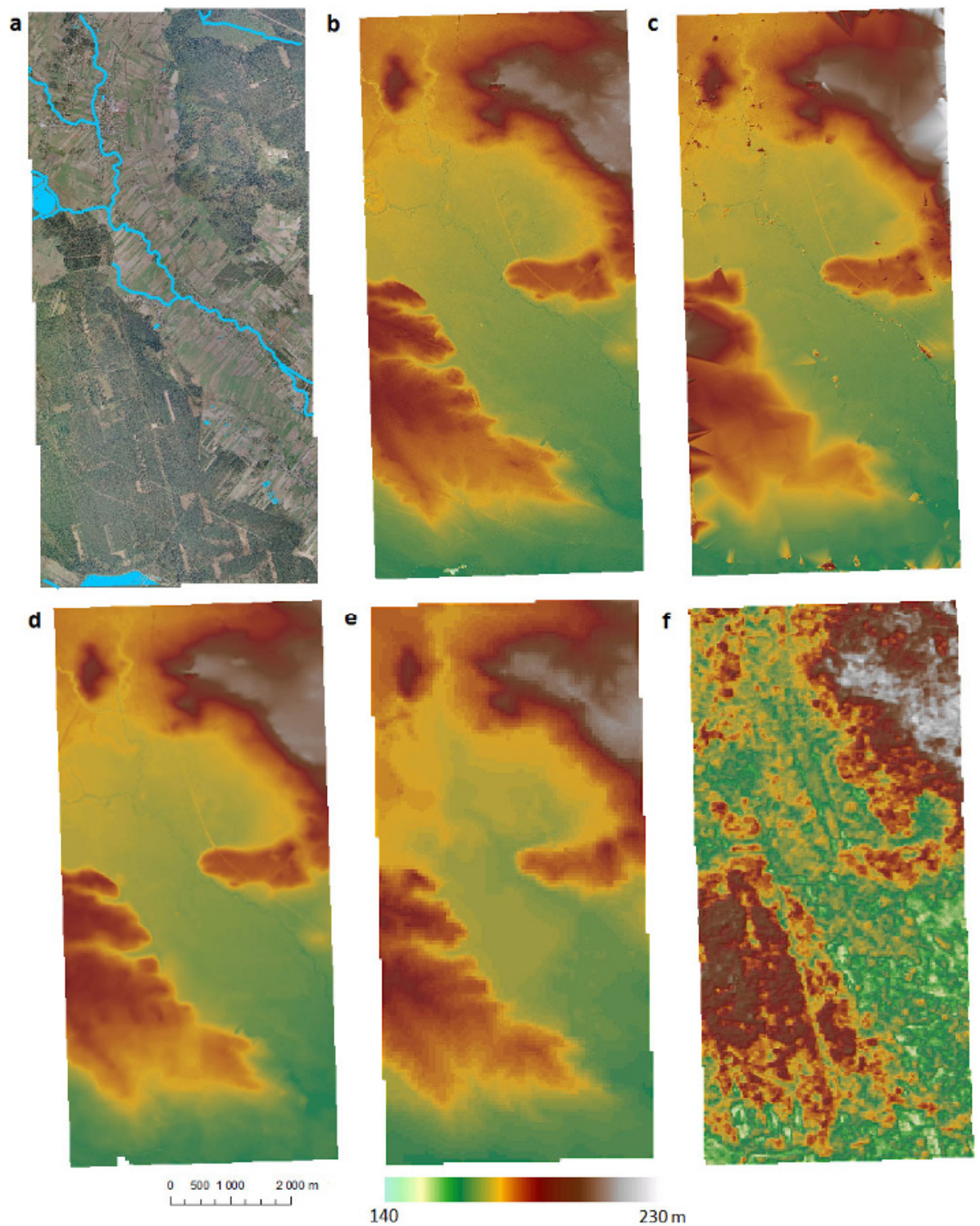

Fig. 1. Test study and data used in research: orthophoto with Czarna Staszowska River highlighted in blue (a); and digital terrain models from various source data: ALS (b), photogrammetry (c), LPIS DTM (d), EuroDEM (e), ASTER GDEM (f).

They confirm the high accuracy of the ALS data related primarily to the robustness to errors associated with low vegetation occurrence, however, a small systematic error (offset) can be noticed, which can be caused by the 
Analysis of vertical accuracy of different DTM sources on the basis of GNSS measurements

\begin{tabular}{|l|c|c|c|c|c|}
\hline Parameter & $\begin{array}{c}\text { ALS } \\
\text { DTM } \\
{[\mathrm{m}]}\end{array}$ & $\begin{array}{c}\text { PHOTO } \\
\text { DTM } \\
{[\mathrm{m}]}\end{array}$ & $\begin{array}{c}\text { LPIS } \\
\text { DTM } \\
{[\mathrm{m}]}\end{array}$ & $\begin{array}{c}\text { EuroDEM } \\
{[\mathrm{m}]}\end{array}$ & $\begin{array}{c}\text { ASTER } \\
\text { GDEM } \\
{[\mathrm{m}]}\end{array}$ \\
\hline Mean & 0.051 & -0.110 & -0.316 & 1.334 & 0.268 \\
Max & 0.546 & 2.307 & 2.510 & 7.077 & 10.976 \\
Min & -0.312 & -2.114 & -2.360 & -1.695 & -10.221 \\
RMSE & 0.171 & 0.624 & 0.950 & 2.686 & 5.081 \\
STD & 0.163 & 0.614 & 0.895 & 2.329 & 5.074 \\
\hline Number of points & 149 & 149 & 161 & 161 & 162 \\
\hline
\end{tabular}

accuracy of georeferencing or incomplete penetration of vegetation by the laser beam (RMSE was slightly higher than the tolerance in the Polish program of countrywide laser scanning). The comparative analysis presented in Table 1 shows that the DTM generated from the available aerial images is 2.5-3 times less accurate than the DTM from ALS in uncovered areas in this case. In forested areas a much lower accuracy should be expected. The vertical accuracy of the DTM from LPIS is four times worse than the ALS-based model. The lowest accuracy (few metres) was noticed for EuroDEM and ASTER GDEM. Additionally, the three last models do not reflect characteristic terrain forms (i.e., embankments), which has an important impact on the results of hydraulic modelling.

\section{METHODOLOGY OF THE RESEARCH}

The research methodology consisted of a series of actions related to the preparation and processing of hydraulic modelling using different elevation data and the development of methods for the assessment of the results.

\subsection{Hydrodynamic model description}

The hydrodynamic model of the Czarna Staszowska River was performed using MIKE software by DHI (http://www.mikepoweredbydhi.com/). The module of MIKE FLOOD was used, which allowed for the combination of 1D and 2D hydraulic models with lateral connections. The hydrodynamic model of the watercourse was made in MIKE 11 (module for onedimensional flow modelling) using hydrological data, cross-sections and observations of engineering structures (bridges, dams). The floodplain models were prepared in MIKE 21 (module for two-dimensional flow modelling) where the digital terrain model (DTM) and digital roughness model (DRM) 
were input data. DRM was created on the basis of the Database of Topographic Objects (Baza Danych Obiektów Topograficznych - BDOT) at a scale of 1:10000 (BDOT is the official topographic database in Poland, stored in the Main Geodetic and Cartographic Documentation Centre). The boundary conditions in the hydraulic model were developed for a water flow of Q1\% - 100 years' discharge (discharge with the exceedance probability $p=1 \%$, once per 100 years). The model was calibrated and validated based on the historical observations of water levels and discharges at the Staszów and Połaniec gauging stations located upstream and downstream of the reach where the two-dimensional modelling was implemented. All hydrological data for each variant were identical and spatial resolution of models was resampled to $5 \mathrm{~m}$ to unify the results of hydraulic modelling. Resampling of ALS-based DTM decreases its resolution (and consequently accuracy), but significantly accelerates the speed of hydraulic calculations, which was justified by studies on quantitative data reduction conducted by Bakuła (2011). For such lowland areas, DTM downgrading to $5 \mathrm{~m}$ is associated with a loss of accuracy of only a few centimetres.

\subsection{Methods of results evaluation}

To analyse the results of hydraulic modelling, a coefficient similar to that used in the assessment of the automatic feature extraction from satellite images (Lee et al. 2003) was adopted. The following cases in the evaluation of the results were considered: true positive (Eq. 1), true negative (Eq. 2), false positive (Eq. 3), false negative (Eq. 4), which can be written in algebra as:

$$
\begin{gathered}
T P=|X \cap R|, \\
T N=|U \backslash(X \cap R)|, \\
F P=|X \backslash R|, \\
F N=|R \backslash X|,
\end{gathered}
$$

where $R$ is a reference set, $X$ is a tested set, $U$ is a space.

In this experiment related to hydraulic modelling, the above-mentioned features represent: $T P$ - inundated areas in both sets $R$ and $X$ (pixel-wised), $T N$ - not inundated areas in both sets $R$ and $X, F P$ - not inundated areas in $R$ and inundated in $X, F N$ - inundated areas in $R$ and not inundated in $X$. In this paper, the results of hydraulic modelling based on DTM from ALS data were used as a reference. Based on these features, correctness $-C R$ (Eq. 5) and completeness $-C P$ (Eq. 6) indexes can be calculated to compare the results: 


$$
\begin{aligned}
& C R=\frac{T P}{T P+F P}, \\
& C P=\frac{T P}{T P+F N} .
\end{aligned}
$$

Correctness $C R$ indicates how many flooded areas, defined by test data set, would be also flooded in the simulation using the most accurate reference data. Completeness $C P$ indicates how many flooded areas defined by the reference data were also identified as flooded by test dataset. For an overall assessment of similarity between two datasets, quality coefficient $Q$ can be used (Eq. 7):

$$
Q=\frac{T P}{T P+F P+F N} .
$$

In the literature, such an index is used for the comparison of two inundation areas (Sole et al. 2008, Yamazaki et al. 2012). It is also known as Jaccard's similarity index. All index values range from 0 to 1 , where values closer to 1 are desired. For the $Q$ index, a value of 0 represents completely different areas and a value of 1 represents perfect agreement. This factor can also be defined as the ratio of the cardinality of dataset intersection and the cardinality of datasets union as follows:

$$
Q=\frac{|X \cap R|}{|X \cup R|},
$$

where $R$ is a reference set, $X$ is a tested set, and $|X|$ is a cardinality of $X$ set.

The second method of result evaluation was the calculation of differences in maximum water depth and maximum flow velocity provided by a comparison of rasters from reference and analysed results of hydraulic modelling. For this analysis statistical parameters were also calculated.

\section{RESULTS}

The results of hydraulic modelling, classified by water depth, are shown in Fig. 2. Each inundation class is visualized here with a shaded terrain model in the background corresponding to the relevant data source. In addition, the result of hydraulic modelling with ALS data (reference inundation area) is marked in each case. A visual interpretation of the results shows a similarity of an analysis conducted using airborne data (Fig. 2a-c). In Fig. 2b a TIN (triangular irregular network) structure is clearly visible, which is caused by a low density of points for forested areas where only stereoscopic measurements could be carried out. EuroDEM, which has a lower spatial resolution (Fig. 2d), represents some differences in terms of reference data (ALS). The part of ASTER GDEM (Fig. 2e) exposes the presence of random vertical 

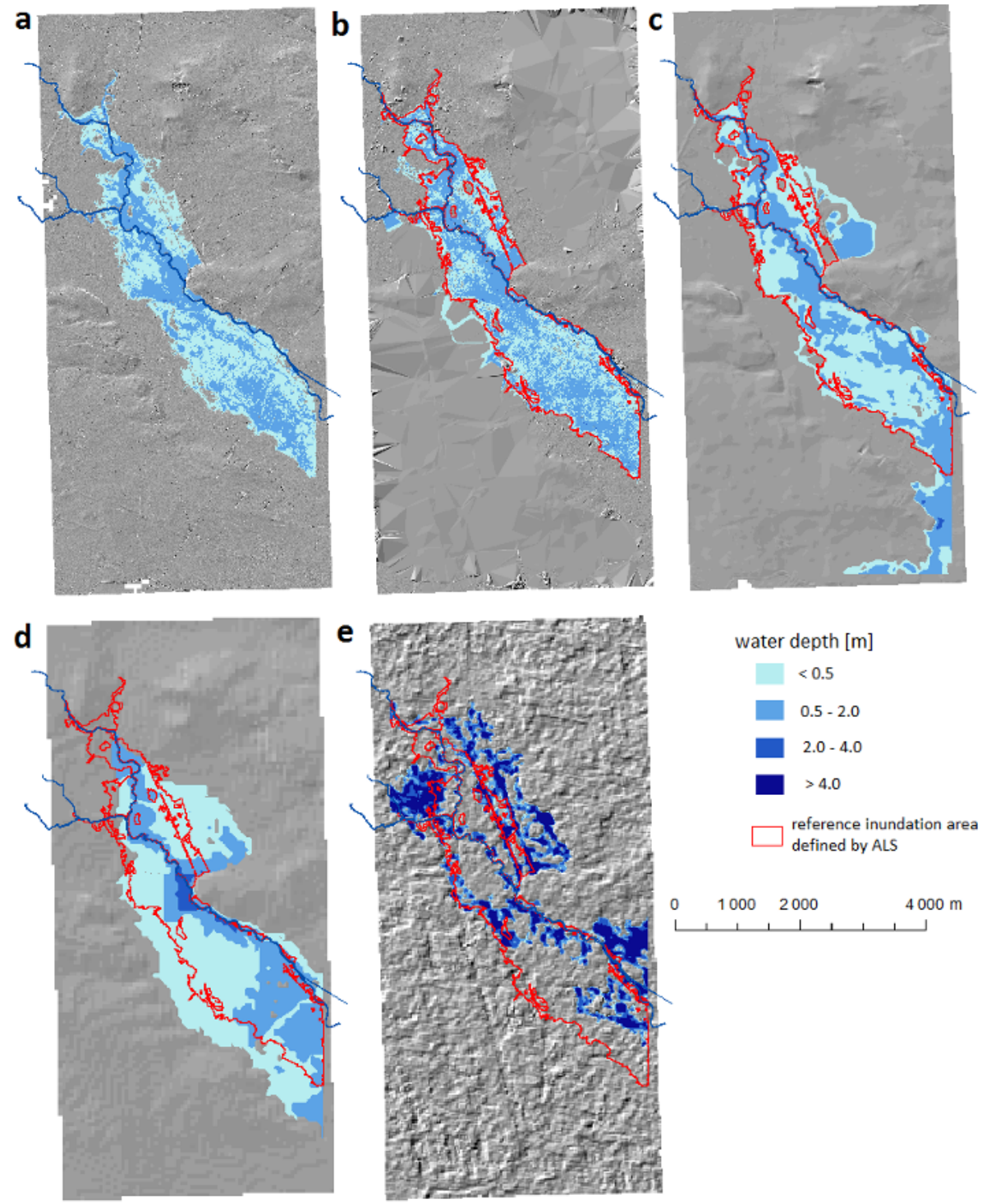

Fig. 2. Results of 2D hydraulic modelling of Czarna Staszowska River using various DTM sources: ALS - reference data (a), matching of aerial images (b), DTM from LPIS (c), EuroDEM (d), and ASTER GDEM (e).

errors in DTM, which significantly influenced the results of hydraulic modelling.

Table 2 shows the values of the following indexes: correctness, completeness, and quality for rasters of inundation zone calculated with different 
elevation data in hydraulic modelling. They were calculated on the basis of the shape of flooded areas. Analysis of this table leads to similar conclusions as the visual assessment. All photogrammetric data indicators determine the maximum level of floodwater and flow velocity of the wave in a similar way (quality, completeness, and correctness indexes are above 0.8). It is worth noting that the high rate of $C P$ index for EuroDEM and LPIS elevation data can be relevant for the determination of flood hazards. The high rate of the $C P$ index provides information that the inundation area, designated by the analysed data source, is also identified by reference data as potentially threatened. The results from Table 2 also prove a significant decrease in similarity in analysis using data at a lower spatial resolution - EuroDEM and ASTER GDEM.

Table 2

Similarity indexes in the analysis of hydraulic modelling using

various elevation data sources in comparison to the results of ALS data application

\begin{tabular}{|c|c|c|c|c|c|c|c|c|c|c|c|c|}
\hline \multirow{2}{*}{ Raster } & \multicolumn{3}{|c|}{ DTM PHOTO } & \multicolumn{3}{|c|}{ DTM LPIS } & \multicolumn{3}{|c|}{ EuroDEM } & \multicolumn{3}{|c|}{ ASTER GDEM } \\
\cline { 2 - 11 } & $C R$ & $C P$ & $Q$ & $C R$ & $C P$ & $Q$ & $C R$ & $C P$ & $Q$ & $C R$ & $C P$ & $Q$ \\
\hline $\begin{array}{c}\text { Indexes } \\
\text { value for } \\
\text { inundation } \\
\text { area quality } \\
\text { assessment }\end{array}$ & 0.88 & 0.95 & 0.84 & 0.72 & 0.94 & 0.69 & 0.59 & 0.89 & 0.55 & 0.43 & 0.32 & 0.23 \\
\hline
\end{tabular}

Table 3

Overall comparison of maximum water depth and flow velocity in comparison to the results of ALS data application

\begin{tabular}{|l|c|r|c|c|c|c|c|c|}
\hline \multirow{2}{*}{ Parameter } & \multicolumn{3}{|c|}{ Maximum water depth $[\mathrm{m}]$} & \multicolumn{3}{c|}{ Maximum flow velocity $[\mathrm{m} / \mathrm{s}]$} \\
\cline { 2 - 9 } & $\begin{array}{c}\text { DTM } \\
\text { PHOTO }\end{array}$ & $\begin{array}{c}\text { DTM } \\
\text { LPIS }\end{array}$ & $\begin{array}{c}\text { Euro } \\
\text { DEM }\end{array}$ & $\begin{array}{c}\text { ASTER } \\
\text { GDEM }\end{array}$ & $\begin{array}{c}\text { DTM } \\
\text { PHOTO }\end{array}$ & $\begin{array}{c}\text { DTM } \\
\text { LPIS }\end{array}$ & $\begin{array}{c}\text { Euro } \\
\text { DEM }\end{array}$ & $\begin{array}{c}\text { ASTER } \\
\text { GDEM }\end{array}$ \\
\hline Mean & 0.07 & 0.01 & 0.14 & 2.99 & -0.01 & 0.01 & -0.04 & -0.08 \\
Median & 0.03 & -0.01 & 0.03 & 2.44 & -0.01 & 0.00 & -0.06 & -0.12 \\
STD & 0.40 & 0.30 & 0.54 & 2.63 & 0.08 & 0.11 & 0.20 & 0.31 \\
MAD & 0.16 & 0.22 & 0.50 & 2.52 & 0.06 & 0.09 & 0.18 & 0.20 \\
RMSE & 0.40 & 0.30 & 0.55 & 3.98 & 0.08 & 0.11 & 0.20 & 0.32 \\
\hline
\end{tabular}

In Table 3, a comparison of the raster presenting maximum water depth and velocity of a flood wave in $2 \mathrm{D}$ hydraulic modelling is shown with respect to a model based on ALS data. In this analysis, the mean value, median value, standard deviation (STD), median absolute deviation (MAD), and root mean square error (RMSE) were calculated. Based on these results, it was 
noticed that photogrammetric data sources provide the most similar effect to LIDAR data in the inundation area and flow velocity prediction. The RMSE for maximum water depth was $0.4 \mathrm{~m}$ in the case of aerial images and $0.3 \mathrm{~m}$ for archived DTM at a slightly lower resolution (LPIS). A difference between MAD and STD for maximum water depth of photogrammetric DTM (PHOTO) could be a result of the appearance of inundated areas in forests, where the accuracy of DTM was much lower due to sparse stereo measurements. Differences in flow velocity reached 0.08 and $0.11 \mathrm{~m} / \mathrm{s}$, respectively. In the considered analysis, very large differences were noticed for DTM from the ASTER satellite.

\section{DISCUSSION}

European good practice on flood mapping described in the EXCIMAP handbook (Martini and Loat 2007) provides only general guidelines for elevation data sources, whereas our investigation and conclusions from other publications point to the significant impact of elevation data on the results of hydraulic modelling (Casas et al. 2006).

The comparative analysis of flood wave propagation proved that the strongest similarity to the inundation area, defined by the most accurate elevation data (ALS), could be reached by using photogrammetric DTMs. This source has huge potential, considering the present images of GSD below $10 \mathrm{~cm}$ acquired by large-format, digital and metric cameras. The development of dense image matching algorithms (Rothermel and Haala 2011) also allows for the creation of elevation models that are competitive to LIDAR data. Nevertheless, the limitation of this technique is a lack of reliable representation of terrain shape in areas covered with vegetation.

Considering DTM from LPIS, the results of hydraulic modelling with its usage do not differ significantly from those associated with image matching. It is worth considering whether this data source could be acceptable in precision 2D hydraulic modelling, because it correctly indicated flood inundation areas (very high index of completeness) in the current research.

The results of hydraulic modelling, based on the DTM obtained by digitations of contours from topographic maps on a scale of 1:50 000, did not provide the correct results. This elevation source represents too low a level of accuracy related to a medium scale of map and large contour intervals. On the other hand, the use of larger scale maps, whose contours are defined on the basis of accurate remote sensing or surveying measurements, can lead to achieving better results in hydraulic modelling using this data source, which was also noted by Casas et al. (2006).

The possibilities of satellite systems elevation data collection are constantly increasing. However, it is very difficult to avoid systematic and ran- 
dom vertical errors, i.e., noise (Jacobsen and Passini 2010), which was particularly visible in our analyses, affecting the accuracy of DTM and preventing raw data usage, and errors related to vegetation and buildings that can impede water flow along river networks (Lehner et al. 2008). Data from the satellite systems do not include the terrain height in the riverbed or small structures such as narrow channels connecting the main river and floodplains (Wilson et al. 2007). These are reasons why many studies depicting examples of the use of satellite data are more often focused on the elimination of systematic and random errors based on data that represent better accuracy and higher resolution. The results of the present study regarding ASTER data do not recommend this data source in 2D hydraulic modelling, showing larger differences in the prediction of water levels and flooding area than in the research by Wang et al. (2012).

\section{CONCLUSION}

This study assessed the influence of an elevation data source of five DTMs (i.e., airborne laser scanning; aerial images on a scale of 13000 ; DTM from national repositories dedicated for orthogonalization of images, LPIS; EuroDEM created from topographic maps on a scale of 1:50000; and ASTER GDEM). Such a validation was carried out using a GNSS evaluation of the vertical accuracy of the datasets and practical research related to hydraulic modelling with the same conditions and parameters for all data series. The following major conclusions can be drawn:

- The geometry of a terrain, described in DTM, is the most influential parameter in hydraulic modelling, and the change of such a data source can affect its results.

- Data from airborne laser scanning have the highest vertical accuracy of the analysed data sources - ALS represents the shape of terrain in the most detailed manner, and its use in 2D hydraulic modelling is nowadays common, but owing to the issue of redundancy and voluminous datasets it should be dedicated to high precision analysis in relatively small areas.

- Photogrammetric data can ensure accuracy quite similar to airborne laser scanning in hydraulic modelling analyses. The only limitation of this technique is in the occurrence of large forested areas where the results of hydraulic modelling may vary due to the problem of the lack of accurate elevation data from this source.

口 Data from DTMs archived in national repositories for aerial image orthorectification or included in topographical databases on a scale of 1:10 000, represented by DTM from the LPIS system, do not provide very high accuracy in hydraulic modelling because of their low $(10-20 \mathrm{~m})$ spatial 
resolution; however, their use can be justified by the absence of more accurate data or integration with a large number of ground-based measurements.

- EuroDEM application in accurate 2D hydraulic modelling led to unsatisfactory results; topographic maps as a source of elevation data should be large-scale, and their contour interval should be small. Nowadays this cartographic elevation data source is seldom used, as highly accurate DTM is archived in national repositories.

口 The poorest quality hydraulic modelling results were obtained using elevation data from ASTER GDEM; satellite data have a worse quality than DTMs from airborne sources, and their application in hydraulic modelling should be limited to the use of very large areas without requiring high precision. However, it can be justified in exceptional situations, for example where political affairs cause an inability to comply with airborne missions in border areas.

- The main criterion for assessing the impact of remote sensing elevation data sources on hydraulic modelling can be their spatial resolution, which has a significant influence on the accuracy of the DTM and, consequently, the result of hydraulic modelling.

Future research in elevation data acquisition for 3D modelling will undoubtedly be focused on the further use of LIDAR data in other geographic areas. The capabilities of constantly developing image matching algorithms will increase. There will also be higher quality and better resolution of aerial images in the development of high accuracy DTM, especially for uncovered areas. Airborne data will not be the only data source offering high accuracy and quality in the near future. The development of radar interferometry and image matching of satellite data, as well as the evolution of accuracy enhancement methods, will unquestionably improve the quality of elevation data from satellites, which will find their use in accurate 2D hydraulic modelling.

Acknowledgements. This research was financed by the Foundation for Polish Science - research grant no. VENTURES/2012-9/1 funded by the Innovative Economy program of the European Structural Funds. We would like to thank to Mr. Radosław Radon from the Regional Water Management Board in Kraków for his indispensable help with hydraulic modelling. 
Bakuła, K. (2011), Reduction of DTM obtained from LiDAR data for flood modeling, Arch. Photogram. Cartogr. Remote Sens. 22, 51-61.

Casas, A., G. Benito, V.R. Thorndycraft, and M. Rico (2006), The topographic data source of digital terrain models as a key element in the accuracy of hydraulic flood modelling, Earth. Surf. Proc. Land. 31, 4, 444-456, DOI: 10.1002/ esp.1278.

Cheveresan, B. (2012), Digital terrain model accuracy for flooded area delineation. In: Proc. 5th Conf. Water Observation and Information System for Decision Support BALWOIS 2012, 27 May - 2 June 2012, Ohrid, Republic of Macedonia.

Directive (2007), Directive 2007/60/EC of the European Parliament and of the Council of 23 October 2007 on the assessment and management of flood risks, Offic. J. Europ. Union L288, 27-34.

Farr, T.G., P.A. Rosen, E. Caro, R. Crippen, R. Duren, S. Hensley, M. Kobrick, M. Paller, E. Rodriguez, L. Roth, D. Seal, S. Shaffer, J. Shimada, J. Umland, M. Werner, M. Oskin, D. Burbank, and D. Alsdorf (2007), The Shuttle Radar Topography Mission, Rev. Geophys. 45, 2, RG2004, DOI: 10.1029/2005RG000183.

French, J.R. (2003), Airborne LiDAR in support of geomorphological and hydraulic modelling, Earth Surf. Proc. Land. 28, 3, 321-335, DOI: 10.1002/esp.484.

Gichamo, T.Z., I. Popescu, A. Jonoski, and D. Solomatine (2012), River crosssection extraction from the ASTER global DEM for flood modeling, Environ. Modell. Softw. 31, 37-46, DOI: 10.1016/j.envsoft.2011.12.003.

Hirschmüller, H. (2008), Stereo processing by semiglobal matching and mutual information, IEEE Trans. Patt. Anal. Mach. Intell. 30, 2, 328-341, DOI: 10.1109/TPAMI.2007.1166.

Höhle, J., and M. Potuckova (eds.) (2011), Assessment of the Quality of Digital Terrain Models, European Spatial Data Research, Official Publ. No. 60, EuroSDR.

Hovenbitzer, M. (2008), The European DEM (EuroDEM) - setup and harmonisation. In: The International Archives of the Photogrammetry, Remote Sensing and Spatial Information Sciences, ISPRS Congress, Beijing, China, Vol. 37, Part B4, 1853-1856.

Jacobsen, K., and R. Passini (2010), Analysis of ASTER GDEM elevation models. In: The International Archives of the Photogrammetry, Remote Sensing and Spatial Information Sciences, ISPRS Congress, Calgary, Canada, Vol. 38, Part 1.

Krieger, G., A. Moreira, H. Fiedler, I. Hajnsek, M. Werner, M. Younis, and M. Zink (2007), TanDEM-X: a satellite formation for high-resolution SAR interferometry, IEEE Trans. Geosci. Remote Sens. 45, 11, 3317-3341, DOI: 10.1109/TGRS.2007.900693. 
Kurczyński, Z. (2006), Aerial and Satellite Imagery of Earth, Warsaw University of Technology Publishing House, Warsaw (in Polish).

Kurczyński, Z., and K. Bakuła (2013), The selection of aerial laser scanning parameters for countrywide digital elevation model creation. In: Proc. 13th SGEM GeoConference on Informatics, Geoinformatics and Remote Sensing, 16-22 June 2013, Vol. 2, 695-702, DOI: 10.5593/SGEM2013/BB2.V2/S10.020.

Lane, S.N., R.J. Hardy, L. Elliott, and D.B. Ingham (2002), High-resolution numerical modelling of three-dimensional flows over complex river bed topography, Hydrol. Process. 16, 11, 2261-2272, DOI: 10.1002/hyp.5034.

Lee, D.S., J. Shan, and J.S. Bethel (2003), Class-guided building extraction from IKONOS imagery, Photogramm. Eng. Remote Sens. 69, 2, 143-150, DOI: 10.14358/PERS.69.2.143.

Lehner, B., K.Verdin, and A. Jarvis (2008), New global hydrography derived from spaceborne elevation data, Eos Trans. Am. Geophys. Union 89, 10, 93-94, DOI: 10.1029/2008EO100001.

Li, Z.L., Q. Zhu, and C. Gold (2005), Digital Terrain Modelling: Principles and Methodology, CRC Press, Boca Raton.

Mandlburger, G., and H. Brockmann (2001), Modelling a watercourse DTM based on airborne laser-scanner data using the example of the River Oder along the German/Polish border. In: Proc. OEEPE Workshop "Airborne Laserscanning and Interferometric SAR for Detailed Digital Elevation Models”, 1-3 March 2001, Stockholm, Sweden, 111-120.

Mandlburger, G., C. Hauer, B. Höfle, H. Habersack, and N. Pfeifer (2009), Optimisation of LiDAR derived terrain models for river flow modelling, Hydrol. Earth Syst. Sci. 13, 8, 1453-1466, DOI: 10.5194/hess-13-1453-2009.

Martini, F., and R. Loat (eds.) (2007), Handbook on Good Practices for Flood Mapping in Europe, European Exchange Circle on Flood Mapping (EXCIMAP), 57 pp.

Miller, C.L., and R.A. Laflamme (1958), The digital terrain model - theory and application, Photogramm. Eng. 24, 433-442.

Rabus, B., M. Eineder, A. Roth, and R. Bamler (2003), The shuttle radar topography mission - a new class of digital elevation models acquired by spaceborne radar, ISPRS J. Photogramm. Remote Sens. 57, 4, 241-262, DOI: 10.1016/ S0924-2716(02)00124-7.

Rauter, H.I., A. Nelson, P. Strobl, W. Mehl, and A. Jarvis (2009), A first assessment of ASTER GDEM tiles for absolute accuracy, relative accuracy and terrain parameters. In: Proc. IEEE Int. Geoscience and Remote Sensing Symp., 1217 July 2009, Cape Town, South Africa, Vol. 5, 240-243, DOI: 10.1109/ IGARSS.2009.5417688.

Rothermel, M., and N. Haala (2011), Potential of dense matching for the generation of high quality digital elevation models. In: The International Archives of the Photogrammetry, Remote Sensing and Spatial Information Sciences, 
ISPRS Workshop, 14-17 June 2011, Hannover, Germany, Vol. 38-4/W19, 271-276.

Sole, A., L. Giosa, L. Nolè, V. Medina, and A. Bateman (2008), Flood risk modelling with LiDAR technology, WIT Trans. Ecol. Environ. 118, 27-36, DOI: 10.2495/FRIAR080031.

Wang, W., X. Yang, and T. Yao (2012), Evaluation of ASTER GDEM and SRTM and their suitability in hydraulic modelling of a glacial lake outburst flood in southeast Tibet, Hydrol. Process. 26, 2, 213-225, DOI: 10.1002/hyp. 8127.

Wehr, A., and U. Lohr (1999), Airborne laser scanning - an introduction and overview, ISPRS J. Photogramm. Remote Sens. 54, 2-3, 68-82, DOI: 10.1016/ S0924-2716(99)00011-8.

Wilson, M., P. Bates, D. Alsdorf, B. Forsberg, M. Horritt, J. Melack, F. Frappart, and J. Famiglietti (2007), Modeling large-scale inundation of Amazonian seasonally flooded wetlands, Geophys. Res. Lett. 34, 15, L15404, DOI: 10.1029/2007GL030156.

Yamazaki, D., C.A. Baugh, P.D. Bates, S. Kanae, D.E. Alsdorf, and T. Oki (2012), Adjustment of a spaceborne DEM for use in floodplain hydrodynamic modeling, J. Hydrol. 436-437, 81-91, DOI: 10.1016/j.jhydrol.2012.02.045.

Received 11 September 2014 Received in revised form 24 May 2015 Accepted 2 June 2015 